\title{
Ultraestrutura do espermatozóide de Ucides cordatus Linnaeus (Crustacea, Ocypodidae) do litoral norte do Brasil ${ }^{1}$
}

\author{
Edilson Matos ${ }^{2}$ \\ Patricia Matos ${ }^{3}$ \\ Laura Corral ${ }^{4}$ \\ Carlos Azevedo ${ }^{4}$
}

\begin{abstract}
Ultrastructure of spermatozoon of the crab Ucides cordatus Linaeus (Crustacea, Decapoda) of the northern littoral of Brazil. Ultrastructure of spermatozoa of the crab Ucides cordatus Linnaeus, 1763 is described and illustrated. Three parts can be distinguished: 1 . the elongate-ovoid acrosome located anteriorly; 2 . the cytoplasmic region; and 3. the nuclear region. The acrosome is composed of a thick electron-dense wall and a less electron-dense subacrosomal space. The cytoplasm region connects the acrosome with the nucleus, and three arms filled with microtubules arise from this region. The nucleus is polymorphous. The spermatozoon of Ucides cordatus follows the general pattern described for other Decapods.

KEY WORDS. Crustacea, Ocypodidae, Ucides cordatus, spermatozoa ultrastructure
\end{abstract}

Os espermatozóides de Crustacea - Decapoda são imóveis, aflagelados e podem ser separados em duas categorias: uniestrelado e multiestrelado (BROWN et al. 1977). Os espermatozóides do tipo multiestrelado consistem de um acrosoma, região citoplasmática, núcleo e um variável número de prolongamentos, os quais podem ter uma origem citoplasmática ou nuclear, ou ambos (POCHON-MASSON 1965; MEDINA 1992). O presente estudo descreve a ultraestrutura do espermatozóide de Ucides cordatus Linnaeus, 1763 que apresenta semelhança ultraestrutural com o espermatozóide de Clibanarius vittatus Bosc, 1802 (MATos et al. 1993).

\section{MATERIAL E MÉTODOS}

Foram utilizados 30 machos adultos de caranguejo Ucides cordatus, coletados na região do município de Bragança $\left(01^{\circ} 03^{\prime} 15^{\prime \prime} \mathrm{S}, 46^{\circ} 46^{\prime} 10^{\prime \prime} \mathrm{W}\right)$, de Augusto Correa $\left(01^{\circ} 01^{\prime} 45^{\prime \prime} \mathrm{S}, 46^{\circ} 38^{\prime} 57^{\prime \prime} \mathrm{W}\right)$, de Marapanim (00 $\left.42^{\prime} 42^{\prime \prime} \mathrm{S}, 47^{\circ} 41^{\prime} 45^{\prime \prime} \mathrm{W}\right)$ e de Primavera $\left(00^{\circ} 56^{\prime} 36^{\prime \prime} \mathrm{S}, 47^{\circ} 07^{\prime} 06^{\prime \prime} \mathrm{W}\right)$ durante todo o ano. Depois da retirada da gônada masculina, pequenos fragmentos foram preparados para visualização de suas estruturas microscópicas sob microscopia eletrônica. Inicialmente procedeu-se fixação em glutaraldeído a 3\% tamponado com cacodilato de sódio a $0,2 \mathrm{M} \mathrm{pH} 7,2$ durante três horas a $4^{\circ} \mathrm{C}$. Depois de lavados no mesmo tampão, durante duas horas

1) Trabalho parcialmente subsidiado pela FCAP, UFPA e Fundação Engenheiro António de Almeida (Portugal).

2) Correspondências para: Departamento de Biologia Animal, Faculdade de Ciências Agrárias do Pará. Avenida Tancredo Neves, 66077-530 Belém, Pará, Brasil.

3) Departamento de Histologia e Embriologia, Universidade Federal do Pará. 66059-900 Belém, Pará, Brasil.

4) Departamento de Biologia Celular, ICBAS, Universidade do Porto. 4050 Porto, Portugal. 

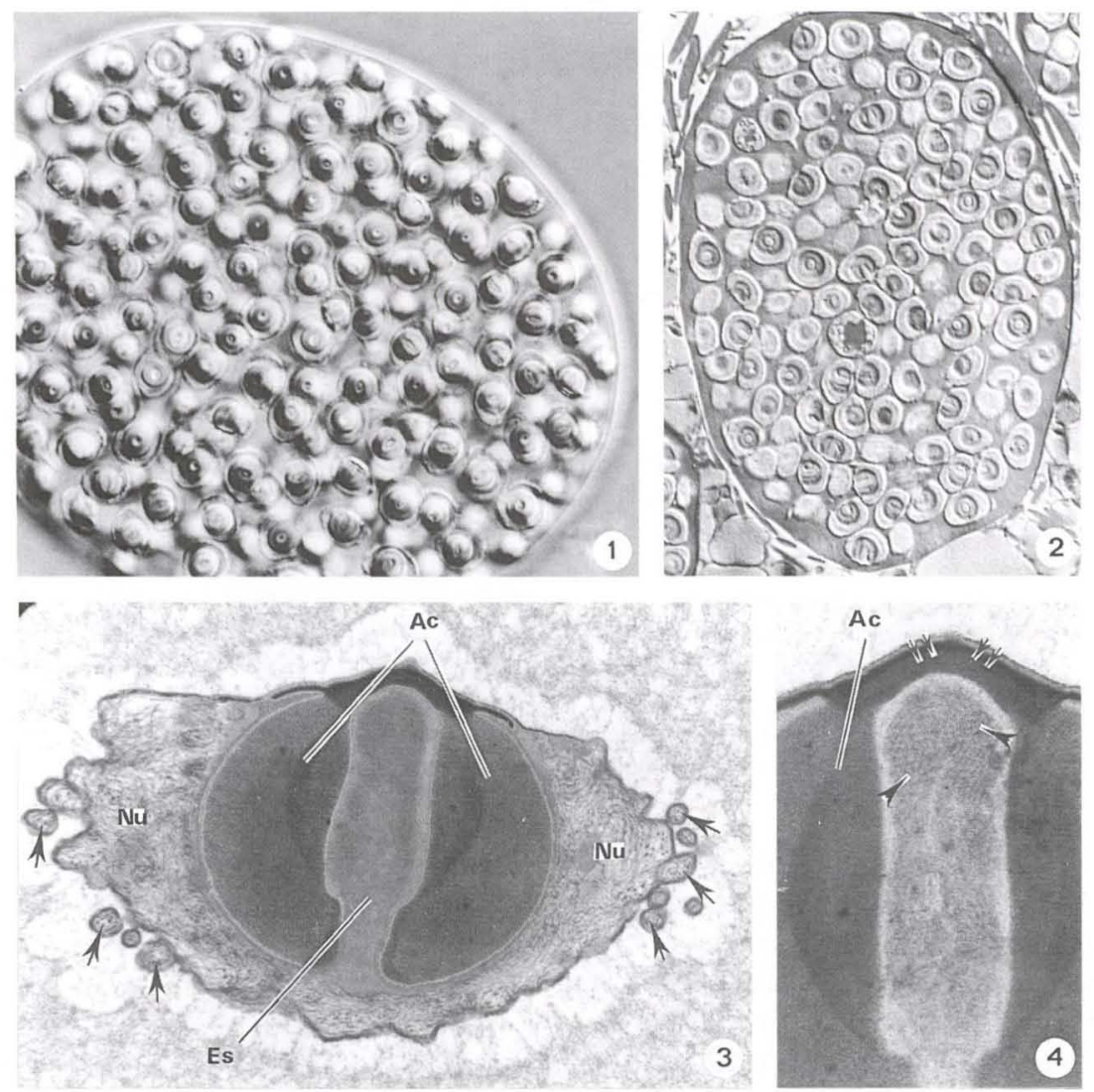

Figs 1-4. (1) Aspecto geral de um cisto com espermatozóides do caranguejo Ucides cordatus, observado "in toto" em M.L. (DIC) Contraste Diferencial de Interferência; (2) um cisto observado em corte semifino em M.L. (DIC); (3) corte longitudinal de um espermatozóide mostrando o acrosoma ( $\mathrm{Ac}$ ), o espaço subacrosômico (Es), o núcleo ( $\mathrm{Nu}$ ) com os seus prolongamentos observados em corte transversal (setas); (4) detalhe do acrosoma (Ac) e do espaço subacrosoômico, onde se observam o filamento axial (cabeças de setas) e a "cap" apical (duplas setas).

a $4^{\circ} \mathrm{C}$, os fragmentos foram pós-fixados, durante duas horas a $4^{\circ} \mathrm{C}$, em tetróxido de ósmio a $2 \%$ devidamente tamponado. Sequencialmente, os fragmentos foram desidratados em série crescente de álcool, seguida de três passagens em óxido de propileno. O material foi incluido em Epon (MATos et al. 1993). As observações foram feitas em cortes semifinos e em cortes ultrafinos, contrastados com acetato de uranila e citrato de chumbo, e observados em microscópio eletrônico JEOL 100CXII operando a $60 \mathrm{Kv}$. Alguns fragmentos de testículo foram pressionados entre lâminas de vidro com glutaraldeído a 3\% tamponado com cacodilato de sódio $0,1 \mathrm{M} \mathrm{pH} \mathrm{7,2,}$ e fixados nesta solução a $4^{\circ} \mathrm{C}$ durante duas horas e após mantidos em tampão de cacodilato de sódio, montados entre lâmina/lamínula e observados em microscopia óptica equipado com contraste de interferência de fase Nomarski (DIC). 


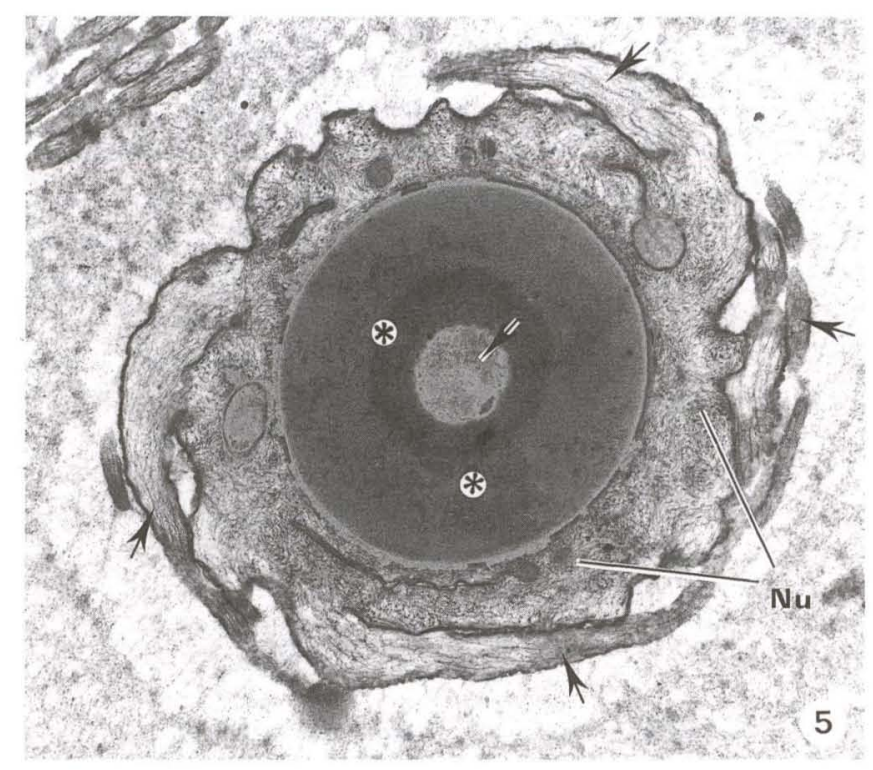

Fig. 5. Corte transversal do espermatozóide mostrando o núcleo ( $\mathrm{Nu})$, os seus prolongamentos (setas), acrosoma ( ${ }^{\star}$ ) e o espaço subacrosômico (seta).

\section{RESULTADOS}

O espermatóforo de Ucides cordatus apresenta cistos contendo espermatozóides em diferentes fases de maturação (Figs 1-2). O espermatozóide consiste de um acrosoma subesferoidal, com região opercular e porção apical livre. Uma camada de citoplasma, contendo remanescentes de organelas celulares, localiza-se entre o acrosoma e o núcleo (Fig. 3). O complexo acrosomal ligeiramente de aspecto elipsoidal, alargado na direção látero-lateral, é ocupado na região anterior pelo opérculo, eletrodenso, ligeiramente convexo e ponteagudo (Fig. 4). A vesícula acrosômica é ocupada pelo espaço subacrosomal, onde se observam o filamento axial e a porção apical, com a região subopercular envolvida por camadas ou pontes concêntricas (Fig. 5). O citoplasma apresenta-se reduzido, com estruturas lamelares e organelas citoplasmáticas, intactas ou degeneradas, com aglutinação de microtúbulos paralelos que formam os prolongamentos ou caudas. $\mathrm{O}$ núcleo abrange localização periférica látero-lateral, separado do citoplasma residual por um complexo de membranas nucleares (Figs 3,5).

\section{DISCUSSÃO}

A morfologia do espermatozóide de Ucides cordatus é comparável a outros Crustacea estudados, tais como Clibanarius vittatus (MATos et al. 1993), Cardisoma carnifex Herbst, 1794 e Varuna litterata Fabricius, 1798 (JAMIESON et al. 1996) e Lithodes maja Linnaeus, 1766 (TUDGE et al. 1998). Já o espermatozóide de Cervimunida johni Portes, 1903 (LOHRMANN \& RAINERI 1995) apresenta características morfológicas bastante diferente do Ucides cordatus, com três regiões bem 
distintas: um acrosoma anterior, alongado; uma região de união citoplasmática com três prolongamentos, e uma região posterior alongada, o núcleo. A morfologia externa do espermatozóide de Ucides cordatus revela braços com região microtubular, a região interna acrosômica apresenta zonas distintas facilmente identificadas, uma cápsula fina eletrodensa e uma invaginação na porção posterior, o perfuratório. $\mathrm{Na}$ porção apical anterior do acrosoma observa-se a região opercular. A zona subopercular apresenta regiões de variada eletrodensidade, estendendo-se posteriormente como uma coluna, semelhante ao descrito por JAMIESON (1989a,b) e HINSCH (1980). O material nuclear é difuso, com possível degeneração da membrana nuclear como foi descrito em Portunus pelagicus Linnaeus, 1766 (JAMIESON. \& TUDGE 1990). O espermatozóide de Ucides cordatus é constituído de três componentes: o acrosoma proeminente, o núcleo polimorfo e parte do citoplasma contendo várias organelas celulares, especialmente seis caudas curtas, implantadas na base e constituída por uma região microtubular.

AGRADECIMENTOS. Ao Sr. João Carvalheiro pelo serviço iconográfico.

\section{REFERÊNCIAS BIBLIOGRÁFICAS}

Brown, A. JR.; P. Talbot; R.G. Summers \& W.H. Clark JR. 1977. Comparative analysis of Decapod sperm. Jour. Cell. Biol. 75: 170-178.

HinsCH, G.W. 1980. Spermiogenesis in Coenobita clypeatus. I. sperm structure. Invert. Reprod. and Develop. 2: 189-198.

JAMIESON, B.G.M. 1989a. Ultrastructural comparison of the spermatozoa of Ranina ranina (Oxystomata) and of other crabs exemplified by Portumus pelagicus (Brachygnaatha0 (Crustacea, Brachyura). Zoomorphology 109: 103-111.

. 1989b. The ultrastructure of the spermatozoa of four species of Xanthid crabs (Crustacea, Brachyura, Xanthidae). Jour. Submicrosc. Cytol. Pathol. 21: 579-584.

Jamieson, B.G.M. \& C.C. TUdGE. 1990. Dorippids are Heterotremata: evidence from ultrastructure of the spermatozoa of Neodorippe astuta (Dorippidae) and Portunus pelagicus (Portunidae) Brachyura:Decapoda. Marine Biology 106: 347-354.

Jamieson, B.G.M.; D. GUINOT \& B. Richer DE Forges. 1996. Contrasting spermatozoal ultrastructure in two thoracotreme crabs, Cardisoma carnifex (Gecarcinidae) and Varuna litterata (Grapsidae) (Crustacea: Brachyura). Invert. Reprod. Develop. 29: 111-126.

LOHRMANN, K. \& M. RAINERI. 1995. Ultrastructure of the spermatozoon of the crab Cervimunida johni Portes, 1903 (Galatheidae, Anomura, Crustacea). Invert. Rep. Devel. 28 (2): 71-76.

Matos, E; P. Matos; E. Oliveira \& C. AzEvedo. 1993. Aspectos morfológicos e ultraestruturais do espermatozóide de ermitão Clibanarius vittatus BOSC, 1802 (Crustacea, Decapoda) do litoral norte do Brasil. Revta Bras. Ciên. Morfol. 10 (2): 126-131.

MEDINA, A. 1992. Structural modifications of sperm from the fiddler crab Uca tangeri (Decapoda) during early stages of fertilization. Jour. Crustacean Biol. 12 (4): 610-614.

Pochon-Masson, J. 1965. L'Ultrastructure des épines du spermatozoide chez les Décapodes (Macroures, Anomoures, Brachyoures). C.R. Acad. Sci. Paris 260: 3762-3764.

Tudge, C.C.; B.G.M. JAmieson; L. SANDBERG \& C. ERSÉUS 1998. Ultrastructure of the mature spermatozoon of the king crab Lithodes maja (Lithodidae, Anomura, Decapoda): further confirmation of a lithodid-pagurid relationship. Invert. Bio. 117 (1): 57-66.

Recebido em 01.VII.1999; aceito em 25.VIII.2000. 